\title{
Dynamic Model of Spur Gear Pair with Modulation Internal Excitation
}

\author{
Zhong Wang, ${ }^{1}$ Lei Zhang, ${ }^{2}$ Yuan-Qing Luo, ${ }^{2}$ and Chang-Zheng Chen ${ }^{1,2}$ \\ ${ }^{1}$ School of Mechanical Engineering, Liaoning Institute of Science and Technology, Benxi, Liaoning, China \\ ${ }^{2}$ School of Mechanical Engineering, Shenyang University of Technology, Shenyang, Liaoning, China
}

Correspondence should be addressed to Lei Zhang; zhangl4869@sina.com

Received 28 November 2016; Revised 27 February 2017; Accepted 15 March 2017; Published 18 April 2017

Academic Editor: Hyeong Joon Ahn

Copyright (C) 2017 Zhong Wang et al. This is an open access article distributed under the Creative Commons Attribution License, which permits unrestricted use, distribution, and reproduction in any medium, provided the original work is properly cited.

In the actual measurements, vibration and noise spectrum of gear pair often exhibits sidebands around the gear mesh harmonic orders. In this study, a nonlinear time-varying dynamic model of spur gear pair was established to predict the modulation sidebands caused by the AM-FM modulation internal excitation. Here, backlash, modulation time-varying mesh stiffness, and modulation transmission error are considered. Then the undamped natural mode was studied. Numerical simulation was made to reveal the dynamic characteristic of a spur gear under modulation condition. The internal excitation was shown to exhibit obvious modulation sideband because of the modulation time-varying mesh stiffness and modulation transmission error. The Runge-Kutta method was used to solve the equations for analyzing the dynamic characteristics with the effect of modulation internal excitation. The result revealed that the response under modulation excitation exhibited obvious modulation sideband. The response under nonmodulation condition was also calculated for comparison. In addition, an experiment was done to verify the prediction of the modulation sidebands. The calculated result was consistent with the experimental result.

\section{Introduction}

The first systematic efforts to analyze the gear dynamics were in the 1920s and early 1930s [1]. Many researchers have made a great contribution to the mathematical models and dynamic behaviors of gear transmission systems. Lumpedparameter models are widely used in modeling the gear pair transmission systems. Kahraman and Singh [2] assumed the shafts and bearings to be rigid and a lumped-parameter model including time-varying mesh stiffness, transmission error, and backlash was developed and solved with Harmonic Balance Method (HBM). Considering the coupled transverse-torsional motion of a spur gear pair, a model of 3 DOF (degrees of freedom) was established by deducing the freedom of the dynamic model [3] and the dynamic equations were solved with HBM and Runge-Kutta method. Then a series of studies were done to reveal the nonlinear behavior of gear-bearing system with backlash and time-varying mesh stiffness by Kahraman et al. [4, 5]. Cai and Hayashi [6] developed a $2 \mathrm{DOF}$ model including time-varying mesh stiffness and transmission error and the calculated result with this $2 \mathrm{DOF}$ linear model was consistent with the experiment result well. In [7], Cai proposed a mathematical method to simulate the time-varying mesh stiffness of helical gear.

Shen et al. [8] solved the single-DOF model of a spur gear pair considering the time-varying mesh stiffness, backlash, and static transmission error with Incremental Harmonic Balance Method (IHBM) and studied the effect of damping coefficient and excitation amplitude. Zhang et al. $[9,10]$ and $\mathrm{Ma}$ et al. [11] developed a model of multishaft helical gear considering geometric eccentricity. Cui et al. [12] studied the effect of revolution speed, backlash of gear pair, radial clearance of bearings, and shaft stiffness on the nonlinear dynamic behavior by a finite element/contact model. Li and Kahraman [13] proposed a tribodynamics model for spur gear pair which couples a mixed elastohydrodynamic lubrication model with a transverse-torsional dynamic model. Liu et al. [14] focused on the nonlinear behavior of a spur gear with backlash by a 2 DOF lumped-parameter model, solved the dynamic equations with Runge-Kutta method, and expounded the influence of revolution speed, backlash, and mesh damping coefficient on the dynamic response. In [15], a 
dynamic model of a spur gear pair is employed to investigate the influence of gear tooth indexing errors on the dynamic response. In [16], philosophy of mathematical phenomenological mapping has been applied to the nonlinear dynamics of spur gears and radial ball bearings. Reference [17] describes a nonlinear dynamic model for the study of the vibration signals generated by gear transmissions. Liu et al. [18] examine the dynamic response of the spur gear pair system and interactions between bearing clearance and the backlash. In [19], a multi-degrees-of-freedom model is presented mathematically to characterize the static transmission error based on fractal theory, investigate the relative sliding friction using an EHL-based friction coefficient formula, and detail the time-varying friction coefficient suitable for HCR gear.

In most studies above, the excitation is usually given under nonmodulation condition. But, in the actual measurements, vibration and noise spectrums of gear pairs often exhibit sidebands around the gear mesh harmonic orders. Blankenship and Singh [20] revealed the modulation sidebands of a spur gear pair by a single-degree-of-freedom model. In [21], the AM-FM modulation characteristic of gear box vibration under nonstationary operating conditions was studied.

To the authors' knowledge, the internal excitation of the spur gear pair caused by the time-varying meshing stiffness and transmission error was usually regarded as nonmodulated signals. In this study, a 6 DOF lumped-parameter model of a spur gear pair considering bearing stiffness, timevarying mesh stiffness, backlash, and transmission errors is established in Section 2.1. The modulation internal excitation that caused the modulation sidebands is discussed in Section 2.2. Numerical simulation is made both under the nonmodulation condition and under modulation condition using Runge-Kutta method in Section 3. Then the calculated results under two conditions are compared. At the end of this study, an experiment is proposed to verify the modulation sidebands predicted by the model which is proposed in Section 2.1.

\section{Dynamic Model of Spur Gear Pair}

2.1. Lumped-Parameter Model. Here, some assumptions are presented to simplify the dynamic model: (a) friction forces at the gear mesh point are neglected, (b) the bearings and shafts that support the gears are modeled by equivalent elements with viscous damping and linear spring, and (c) the mesh damping is modeled by equivalent element with viscous damping. The simplified mechanical model to predict the modulation sidebands of a spur gear pair is established in Figure 1.

As shown in Figure $1, x_{1} / x_{2}$ and $y_{1} / y_{2}$ are the translational displacements of the driving/driven gear, $\theta_{1} / \theta_{2}$ is the torsional displacement of the driving/driven gear, $r_{1} / r_{2}$ is the base circle radii of the driving/driven gear, and $\alpha$ is the pressure angle.

The relative gear mesh displacement $\delta$ is defined as

$$
\begin{aligned}
\delta= & x_{1} \sin \alpha-y_{1} \cos \alpha+r_{1} \theta_{1}-x_{2} \sin \alpha+y_{2} \cos \alpha \\
& +r_{2} \theta_{2}+e_{r},
\end{aligned}
$$

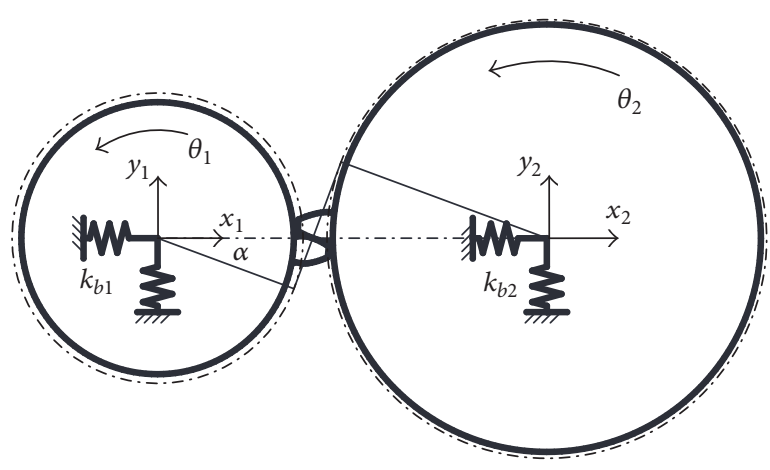

FIGURE 1: Mechanical model.

where $e_{r}$ is the transmission error. The backlash nonlinearity function, $f(\delta)$, is defined as

$$
f(\delta)= \begin{cases}\delta-b & \delta>b \\ 0 & -b \leq \delta \leq b \\ \delta+b & \delta<-b\end{cases}
$$

where $b$ is the half-backlash value.

Define the dynamic gear mesh force $F_{m}(t)$ as

$$
F_{m}(t)=c_{m} \dot{\delta}+k_{m}(t) f(\delta)
$$

where $c_{m}$ is the mesh damping of the spur gear pair system and $k_{m}(t)$ is the time-varying mesh stiffness.

Equations of multi-degrees-of-freedom motion of spur gear pair with lumped-parameter method are written as follows:

$$
\begin{aligned}
m_{1} \ddot{x}_{1}+c_{b 1} \dot{x}_{1}+k_{b 1} x_{1} & =-F_{m} \sin \alpha, \\
m_{1} \ddot{y}_{1}+c_{b 1} \dot{y}_{1}+k_{b 1} y_{1} & =-m_{1} g+F_{m} \cos \alpha, \\
J_{1} \ddot{\theta}_{1} & =T_{d}-r_{1} F_{m}, \\
m_{2} \ddot{x}_{2}+c_{b 2} \dot{x}_{2}+k_{b 2} x_{2} & =F_{m} \sin \alpha, \\
m_{2} \ddot{y}_{2}+c_{b 2} \dot{y}_{2}+k_{b 12} y_{2} & =-m_{2} g-F_{m} \cos \alpha, \\
J_{2} \ddot{\theta}_{2} & =T_{l}-r_{2} F_{m},
\end{aligned}
$$

where $m_{1} / m_{2}$ is the mass of driving/driven gear, $J_{1} / J_{2}$ is the rotational inertia of driving/driven gear, $c_{b 1} / c_{b 2}$ is the damping of driving/driven gear, $k_{b 1} / k_{b 2}$ is the bearing support stiffness, and $T_{d} / T_{l}$ is the input/output torque of the spur gear pair system.

2.2. Excitation of the Spur Gear Pair System. The input torque and output torque are assumed to be constant; namely, $T_{d}=T_{d m}$ and $T_{l}=T_{l m}$. The high-frequency internal excitation of the time-varying mesh stiffness $k_{m}(t)$ and transmission error $e_{r}(t)$ caused by transmission error is considered in the formulations as shown in (5)-(8c). 
In the nonmodulation form, the time-varying mesh stiffness $k_{m}(t)$ and the static transmission error $e(t)$ are usually written as follows:

$$
\begin{aligned}
& k_{m}(t)=\bar{k}_{m}\left[1+\sum_{j=1}^{N} \widehat{k}_{m}^{(j)} \sin \left(j \omega_{m} t+\varphi_{m}^{(j)}\right)\right], \\
& e_{r}(t)=\bar{e}_{r}\left[1+\sum_{j=1}^{N} \widehat{e}_{r}^{(j)} \sin \left(j \omega_{m} t+\varphi_{r}^{(j)}\right)\right] .
\end{aligned}
$$

In (5), $\omega_{m}$ is the mesh frequency, $\bar{k}_{m}$ is the mean mesh stiffness value, $\widehat{k}_{m}^{(j)}$ is the dimensionless jth harmonic amplitude coefficient, and $\varphi_{m}^{(j)}$ is the dimensionless $j$ th phase angle. Meanwhile, in (6), $\bar{e}_{r}$ is the mean error displacement, $\hat{e}_{r}^{(j)}$ is the amplitude coefficient of the $j$ th harmonic terms, and $\varphi_{r}^{(j)}$ is the dimensionless $j$ th phase angle.

If the system was to be exercised with the internal excitation defined as (5) and (6), the dynamic mesh force would observe little or no modulation sidebands and as a result the nonlinear response will observe little or no modulation sidebands.

The modulation time-varying mesh stiffness is rewritten as $(7 \mathrm{a}),(7 \mathrm{~b})$, and $(7 \mathrm{c})$.

$$
k_{m}(t)=\bar{k}_{m}\left[1+\sum_{j=1}^{N} \widehat{k}_{m}^{(j)} A^{(j)} \sin \left(j B^{(j)} \omega_{m} t+\varphi_{m}^{(j)}\right)\right] .
$$

Here, $A^{(j)} / B^{(j)}$ are the dimensionless $j$ th modulation coefficients of amplitude/frequency, which are defined as follows:

$$
\begin{aligned}
A^{(j)}= & +\alpha_{1}^{(j)} \sin \left(j \omega_{1} t+\varphi_{1 \alpha}^{(j)}\right) \\
& +\alpha_{2}^{(j)} \sin \left(j \omega_{2} t+\varphi_{2 \alpha}^{(j)}\right), \\
B^{(j)}= & +\beta_{1}^{(j)} \sin \left(j \omega_{1} t+\varphi_{1 \beta}^{(j)}\right) \\
& +\beta_{2}^{(j)} \sin \left(j \omega_{2} t+\varphi_{2 \beta}^{(j)}\right) .
\end{aligned}
$$

In (7b), $\alpha_{1}^{(j)} / \alpha_{2}^{(j)}$ is the modulation amplitude coefficient of the $j$ th harmonic term of driving/driven gear and $\varphi_{1 \alpha}^{(j)} / \varphi_{2 \alpha}^{(j)}$ is the corresponding phase angle. For $(7 c), \beta_{1}^{(j)} / \beta_{2}^{(j)}$ is the modulation frequency coefficient of the $j$ th harmonic term of driving/driven gear and $\varphi_{1 \beta}^{(j)} / \varphi_{2 \beta}^{(j)}$ is the corresponding phase angle.

Like (7a), (7b), and (7c), the static transmission error $e(t)$ is rewritten as

$$
\begin{aligned}
e_{r}(t)= & \bar{e}_{r}\left[1+\sum_{j=1}^{N} \widehat{e}_{r}^{(j)} C^{(j)} \sin \left(j D^{(j)} \omega_{m} t+\varphi_{r}^{(j)}\right)\right], \\
C^{(j)}= & 1+\chi_{1}^{(j)} \sin \left(j \omega_{1} t+\varphi_{1 \chi}^{(j)}\right) \\
& +\chi_{2}^{(j)} \sin \left(j \omega_{2} t+\varphi_{2 \chi}^{(j)}\right),
\end{aligned}
$$

TABLE 1: System parameters of gear transmission.

\begin{tabular}{lcc}
\hline & Driving gear & Driven gear \\
\hline Number of teeth & 55 & 75 \\
Module $/ \mathrm{mm}$ & 2 & 2 \\
Face width $/ \mathrm{mm}$ & 30 & 29 \\
Pressure angle $/ \mathrm{deg}$ & 22.5 & 22.5 \\
Mass $/ \mathrm{kg}$ & 2.034 & 3.937 \\
Rotational inertia $/ \mathrm{kg} \cdot \mathrm{m}^{2}$ & 0.0033 & 0.0115 \\
Mean mesh stiffness $/ \mathrm{N} \cdot \mathrm{m}^{-1}$ & \multicolumn{2}{c}{$4.48 \times 10^{8}$} \\
Support stiffness of bearing $/ \mathrm{N} \cdot \mathrm{m}^{-1}$ & \multicolumn{2}{c}{$2.6 \times 10^{8}$} \\
Mesh damping $/ \mathrm{N} \cdot \mathrm{s} \cdot \mathrm{m}^{-1}$ & \multicolumn{2}{c}{800} \\
Support damping of bearing $/ \mathrm{N} \cdot \mathrm{s} \cdot \mathrm{m}^{-1}$ & \multicolumn{2}{c}{500} \\
Mean transmission error $/ \mu \mathrm{m}$ & \multicolumn{2}{c}{20} \\
Backlash $/ \mu \mathrm{m}$ & \multicolumn{2}{c}{20} \\
\hline
\end{tabular}

$$
\begin{aligned}
D^{(j)}= & +\gamma_{1}^{(j)} \sin \left(j \omega_{1} t+\varphi_{1 \gamma}^{(j)}\right) \\
& +\gamma_{2}^{(j)} \sin \left(j \omega_{2} t+\varphi_{2 \gamma}^{(j)}\right),
\end{aligned}
$$

where $\chi_{1}^{(j)} / \chi_{2}^{(j)}$ and $\gamma_{1}^{(j)} / \gamma_{2}^{(j)}$ are the modulation amplitude coefficient and modulation frequency coefficient of $j$ th harmonic term of the driving/driven gear and $\varphi_{1 \chi}^{(j)}, \varphi_{1 \chi}^{(j)}, \varphi_{1 \gamma}^{(j)}$, and $\varphi_{1 \gamma}^{(j)}$ are the corresponding phase angles.

\section{Numerical Simulation}

Numerical simulations are carried out to investigate the modulation sidebands of the spur gear pair and a pair of spur gears are taken as an example and the system parameters of gear transmission are shown in Table 1. The Runge-Kutta method is used for solving the dynamic equations given in (4) with the modulation transmission errors given in (7a), (7b), and $(7 \mathrm{c})$ and modulation time-varying mesh stiffness given in (8a), (8b), and (8c).

Neglecting gear mesh damping and bearing support damping and considering the time-varying mesh stiffness $k_{m}(t)$ as a constant $\bar{k}_{m}$, with the values of basic design parameters defined in Table 1, the six undamped natural modes of the lumped-parameter model of spur gear pair are determined as rigid-body mode at $0 \mathrm{~Hz}$, gear pair mode at $1149 \mathrm{~Hz}$, translational mode of driven gear at $1293 \mathrm{~Hz}$, gear pair mode at $1604 \mathrm{~Hz}$, translational mode of driving gear at $1799 \mathrm{~Hz}$, and gear pair mode at $5043 \mathrm{~Hz}$, and the corresponding natural mode types are shown in Figure 2.

For further calculation, the mean mesh stiffness $\bar{k}_{m}$ and mean transmission error $\bar{e}_{r}$ are defined as shown in Table 1 . Considering only the fundamental wave of $k_{m}(t)$ and $e_{r}(t)$, the corresponding modulation parameters in (7a)-(8c) are defined as $\widehat{k}_{m}^{(j)}=0.3, \varphi_{m}^{(1)}=0, \alpha_{1}^{(1)}=0.055, \alpha_{2}^{(2)}=0.049$, $\varphi_{1 \alpha}^{(1)}=\pi / 5, \varphi_{2 \alpha}^{(1)}=3 \pi / 2, \beta_{1}^{(1)}=\beta_{2}^{(1)}=7 \times 10^{-5}, \varphi_{1 \beta}^{(1)}=0$, $\varphi_{2 \beta}^{(1)}=\pi / 8, \widehat{e}_{r}^{(1)}=1.5, \varphi_{r}^{(1)}=\pi / 2, \chi_{1}^{(1)}=0.032, \chi_{2}^{(1)}=0.35$, $\varphi_{1 \chi}^{(1)}=\pi / 3, \varphi_{2 \chi}^{(1)}=\pi / 2, \gamma_{1}^{(j)}=\gamma_{2}^{(j)}=7 \times 10^{-5}, \varphi_{1 \gamma}^{(1)}=\pi / 4$, and $\varphi_{2 \gamma}^{(1)}=\pi / 6$. 


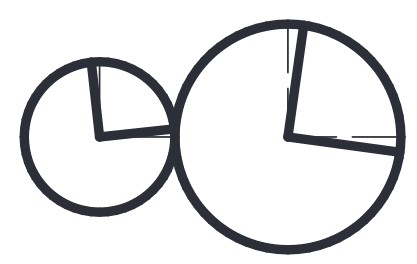

(a)

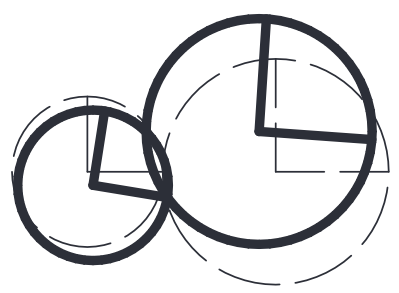

(b)

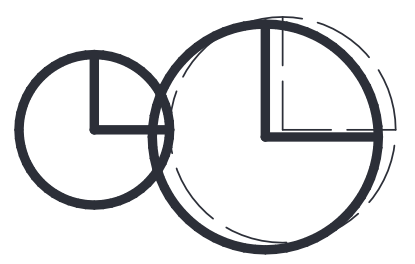

(c)

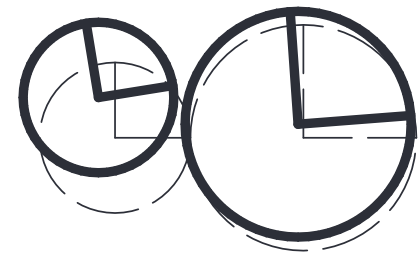

(d)

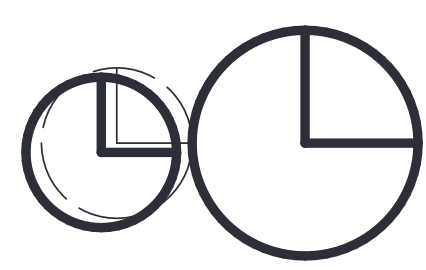

(e)

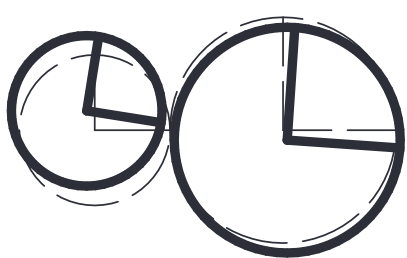

(f)

FiguRE 2: Mode types of spur gear pair.

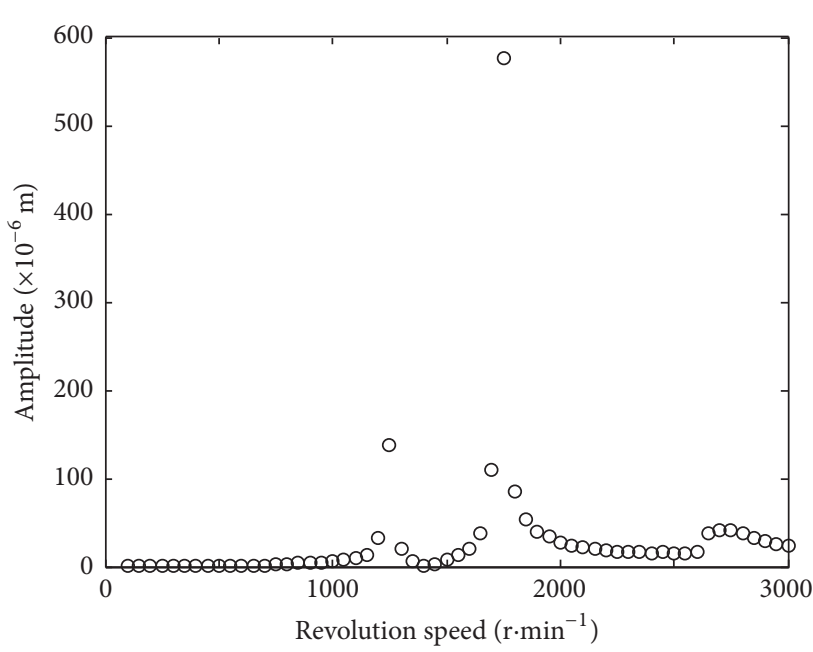

(a)

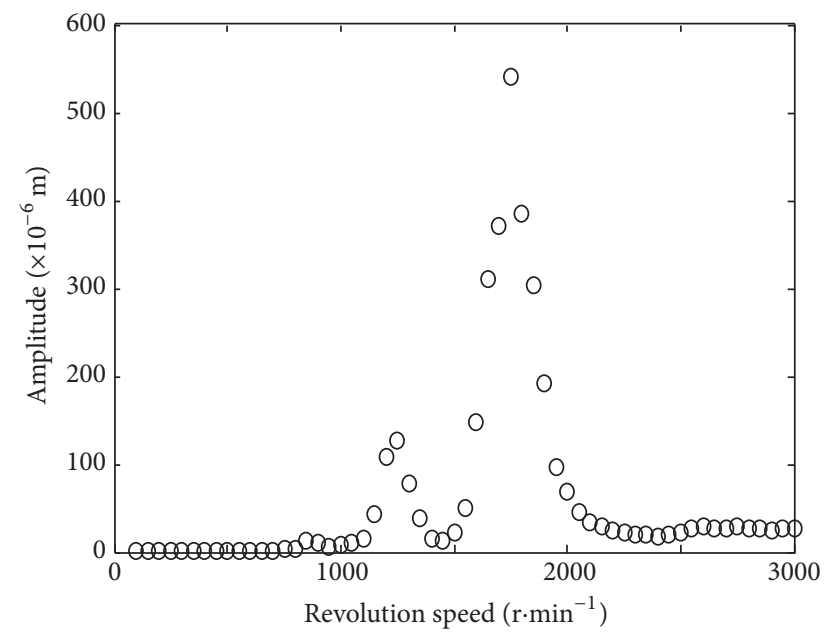

(b)

FIGURE 3: Amplitude condition at different revolution speed: (a) under nonmodulation condition and (b) under modulation condition.

The dynamic equations are solved where the input revolution speed is used as a control parameter. The relationship between amplitude of displacement along $y$-axis of driving gear and input revolution speed is shown in Figure 3.

The calculated undamped resonance frequency is mostly distributed in $1.2-1.8 \mathrm{kHz}$, and the corresponding input revolution speed of driving gear is distributed in $1000-2000 \mathrm{r} / \mathrm{min}$. It can be observed that two peaks appear at $1250 \mathrm{r} / \mathrm{min}$ and $1750 \mathrm{r} / \mathrm{min}$ both in Figures 3(a) and 3(b). As shown in Figure 3, the resonant frequency bands under modulation condition are broader than corresponding ones under nonmodulation condition.

For better clarity, the response of the spur gear pair under off-resonance conditions at the input revolution speed of $1500 \mathrm{r} / \mathrm{min}$ is further expounded in Section 3.1 and the response under near-resonance conditions at the input revolution speed of $1800 \mathrm{r} / \mathrm{min}$ is further expounded in Section 3.2.

3.1. Response under Off-Resonance Condition. Define the internal excitation as $F_{\text {in }}(t)=e_{r}(t) \cdot k_{m}(t)$. The transmission error and time-varying mesh stiffness are predicted using (5)-(6) under nonmodulation condition and using (7a)-(8c) under modulation condition. The two kinds of internal excitation are calculated and the results are shown in Figure 4. Here, $x$-axis presents frequency and $y$-axis presents the relative internal excitation defined as $F_{\text {in }} / F_{\text {mean }}$. Here, $F_{\text {mean }}$ is the mean value of $F_{\text {in }}$.

While the input revolution speed is $1500 \mathrm{r} / \mathrm{min}$, only two peaks appear at $1375 \mathrm{~Hz}$ and $2750 \mathrm{~Hz}$ in the internal excitation spectrum under nonmodulation condition as shown in Figure 4(a). For the modulation condition, as shown in 


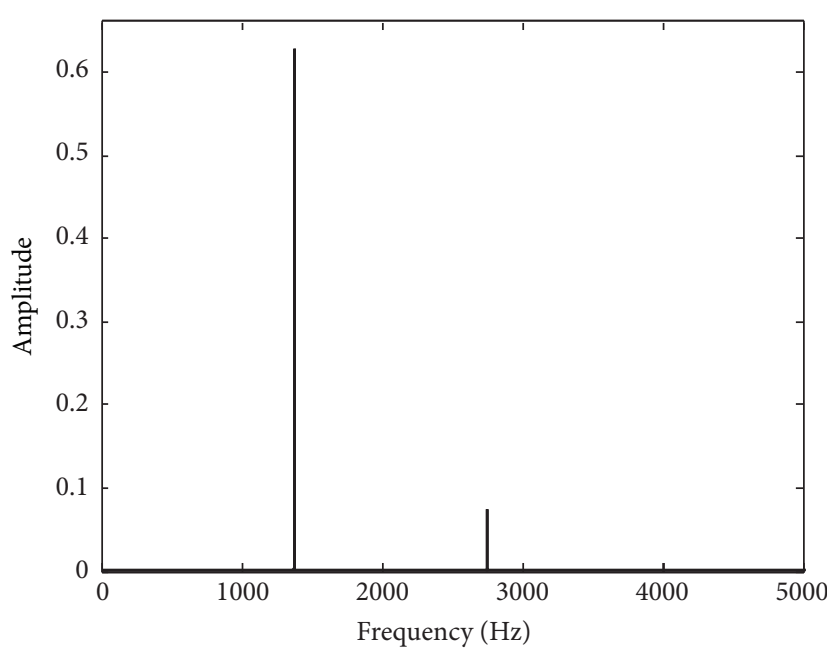

(a)

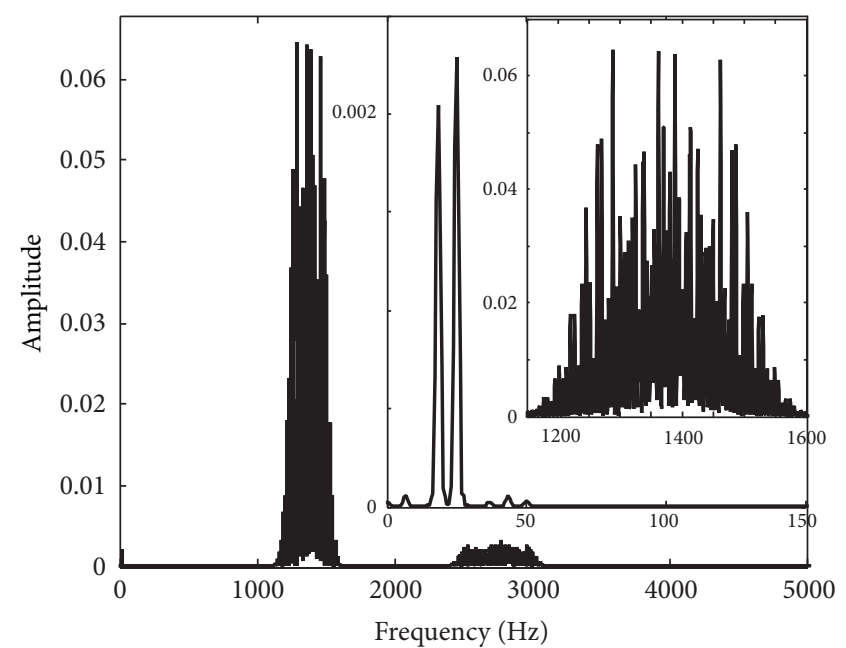

(b)

FIgURE 4: Internal excitation at $1500 \mathrm{r} / \mathrm{min}$ : (a) under nonmodulation condition and (b) under modulation condition.

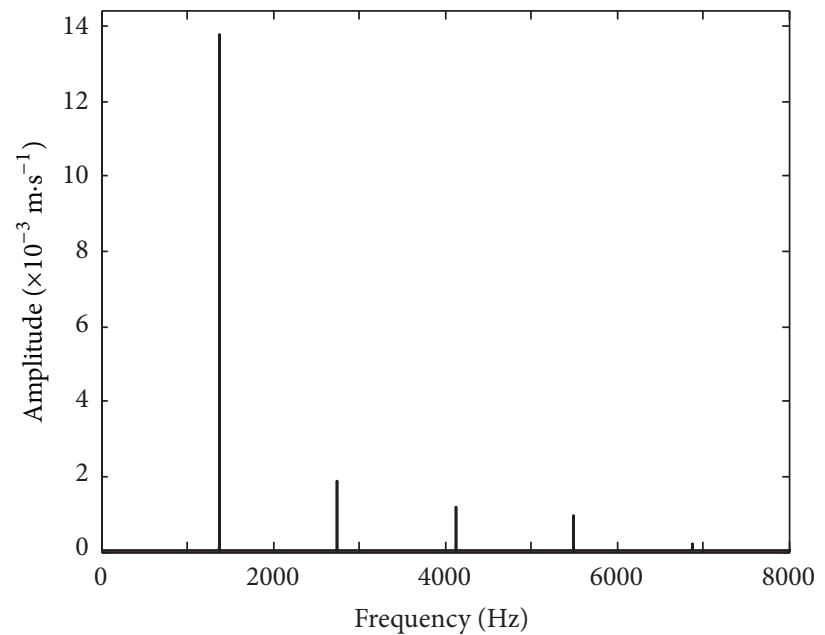

(a)

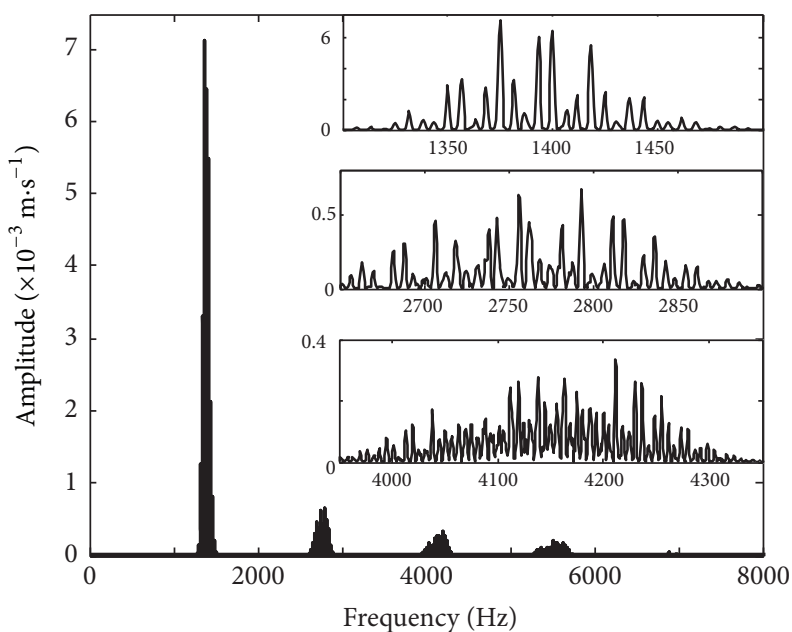

(b)

FIGURE 5: Response at $1500 \mathrm{r} / \mathrm{min}$ : (a) under nonmodulation condition and (b) under modulation condition.

Figure 4(b), the modulation sidebands at $f_{m}=1375 \mathrm{~Hz}$ and $2 f_{m}=2750 \mathrm{~Hz}$ are obvious. In addition, two peaks at input revolution frequency of $f_{i}=25 \mathrm{~Hz}$ and output revolution frequency of $f_{o}=18.3 \mathrm{~Hz}$ are obvious.

To study the nonlinear dynamic behaviors of spur gear pair under off-resonance condition at revolution speed of $1500 \mathrm{r} / \mathrm{min}$, the internal excitation under nonmodulation condition as shown in Figure 4(a) and that under modulation condition as shown in Figure 4(b) are applied to the system. The response of the input bearing along $y$-axis under nonmodulation condition is shown in Figure 5(a) and the response of the input bearing along $y$-axis under modulation condition is shown in Figure 5(b). Under the nonmodulation condition, four peaks appear in the speed spectrum at the mesh harmonic order of $f_{m}=1375 \mathrm{~Hz}, 2 f_{m}=2750 \mathrm{~Hz}$, $3 f_{m}=4125 \mathrm{~Hz}$, and $4 f_{m}=5500 \mathrm{~Hz}$ and the peak at $f_{m}=1375 \mathrm{~Hz}$ is the max one. The sidebands disappear in the speed spectrum as shown in Figure 5(b). Under the modulation condition, sidebands appear around the mesh harmonic order of $f_{m}=1375 \mathrm{~Hz}, 2 f_{m}=2750 \mathrm{~Hz}, 3 f_{m}=$ $4125 \mathrm{~Hz}$, and $4 f_{m}=5500 \mathrm{~Hz}$.

3.2. Response under Near-Resonance Condition. For revealing the modulation response of the spur gear pair under nearresonance condition, the input revolution speed of $1800 \mathrm{r} / \mathrm{min}$ is applied to the gear-bearing system. The internal excitation under nonmodulation form and that under modulation form are shown in Figure 6.

At the revolution speed of $1800 \mathrm{r} / \mathrm{min}$, the spur gear pair is under near-resonance condition as shown in Figures 6(a) and 6(b). Both internal excitation under nonmodulation condition and that under modulation condition at revolution speed of $1800 \mathrm{r} / \mathrm{min}$ are similar to the corresponding ones at revolution speed of $1500 \mathrm{r} / \mathrm{min}$. For the nonmodulation 


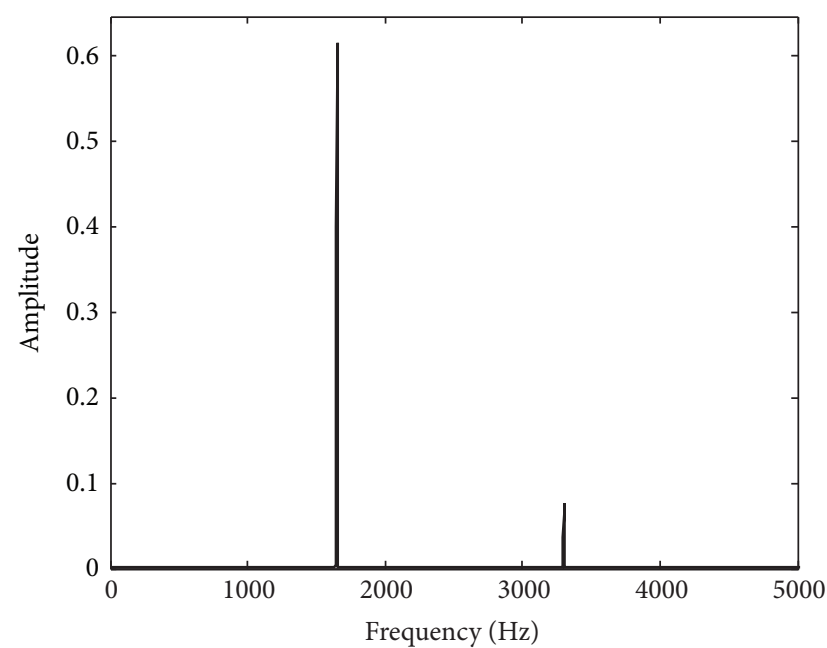

(a)

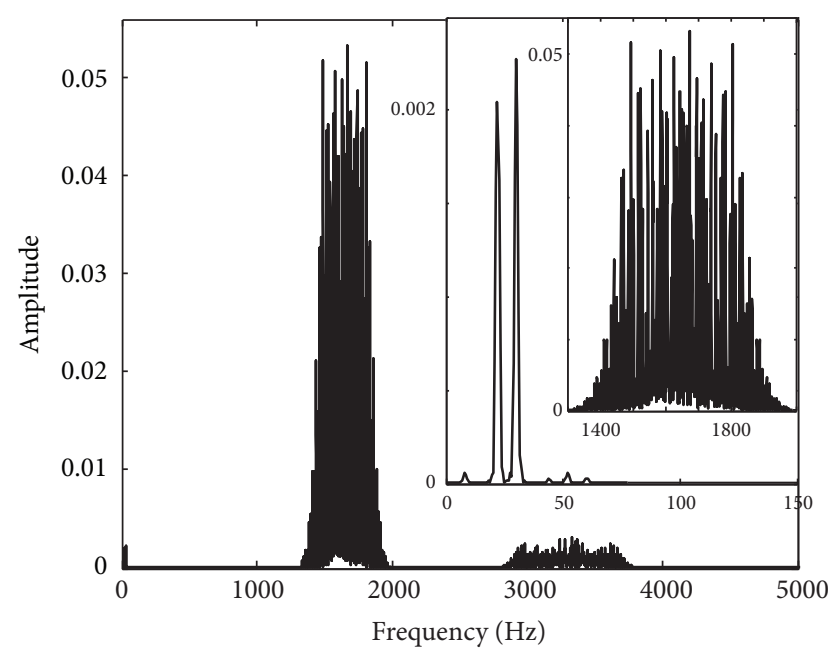

(b)

FIGURE 6: Internal excitation at $1800 \mathrm{r} / \mathrm{min}$ : (a) under nonmodulation condition and (b) under modulation condition.

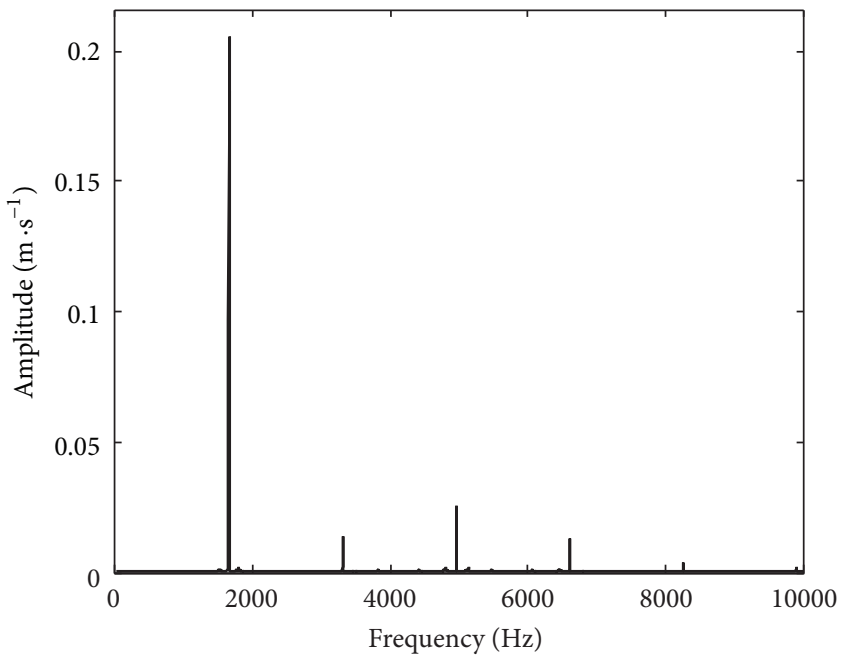

(a)

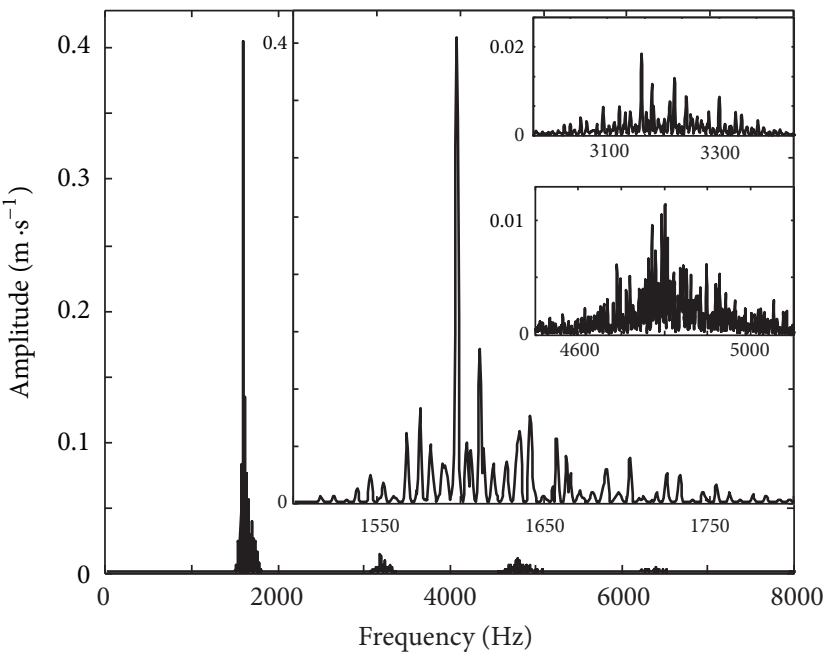

(b)

FIGURE 7: Response at $1800 \mathrm{r} / \mathrm{min}$ : (a) under nonmodulation condition and (b) under modulation condition.

condition, only two peaks appear in the spectrum at $f_{m}=$ $1650 \mathrm{~Hz}$ and $2 f_{m}=3300 \mathrm{~Hz}$ as shown in Figure 6(a) and the sidebands disappear. For the modulation condition, sidebands appear around the mesh harmonic order of $f_{m}=$ $1650 \mathrm{~Hz}$ and $2 f_{m}=3300 \mathrm{~Hz}$. In addition, two more peaks appear in the spectrum at input revolution frequency of $f_{i}=$ $29.91 \mathrm{~Hz}$ and output revolution frequency of $f_{o}=21.97 \mathrm{~Hz}$.

To reveal the nonlinear dynamic response of the spur gear pair under near-resonance conditions, the internal excitation shown in Figure 6(a) and that shown in Figure 6(b) are applied to the system. The dynamic response of driving gear bearing along $y$-axis under nonmodulation condition is shown in Figure 7(a) and the one under modulation condition is shown in Figure 7(b).

For the nonmodulation condition, the frequency components under near-resonance condition are more complex than the ones under off-resonance condition. As shown in Figure 7(a), the peaks appear at mesh harmonic orders of $f_{m}=1650 \mathrm{~Hz}, 2 f_{m}=3300 \mathrm{~Hz}, 3 f_{m}=4950 \mathrm{~Hz}, 4 f_{m}=$ $6600 \mathrm{~Hz}$, and $5 f_{m}=8250 \mathrm{~Hz}$ and the main peak appears at $f_{m}=1650 \mathrm{~Hz}$. In addition, some of the energy of the gear mesh harmonic order at frequency of $f_{m}=1650 \mathrm{~Hz}$, $2 f_{m}=3300 \mathrm{~Hz}, 3 f_{m}=4950 \mathrm{~Hz}$, and $4 f_{m}=6600 \mathrm{~Hz}$ is distributed to small sidebands. For the modulation condition, four sidebands around mesh harmonic order at frequency of $f_{m}=1650 \mathrm{~Hz}, 2 f_{m}=3300 \mathrm{~Hz}, 3 f_{m}=4950 \mathrm{~Hz}$, and $4 f_{m}=6600 \mathrm{~Hz}$ appear in the speed spectrum of the driving gear bearing along $y$-axis as shown in Figure 7(b) and the main peak appears at frequency of $f_{m}=1650 \mathrm{~Hz}$. The peak value appearing at mesh frequency under modulation condition at revolution speed of $1800 \mathrm{r} / \mathrm{min}$ is much larger than the corresponding one under nonmodulation condition. 


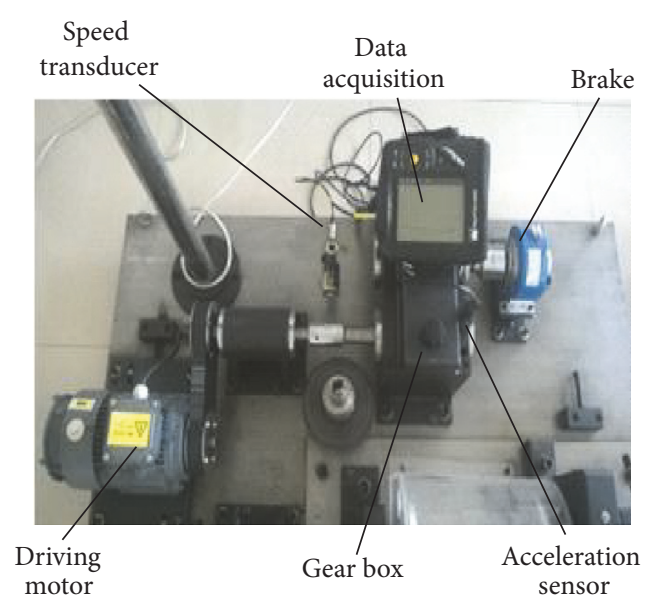

(a)

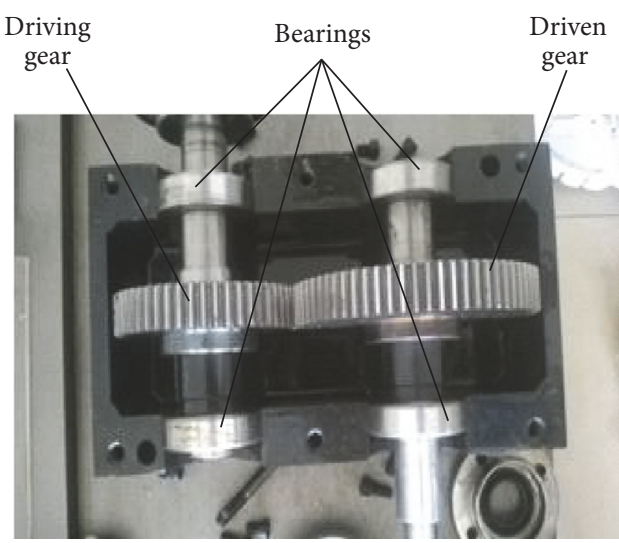

(b)

Figure 8: Experimental set.

The sideband around gear mesh harmonic order at frequency of $f_{m}=1650 \mathrm{~Hz}$ is not symmetric to mesh frequency.

\section{Experimental Validation}

An experiment is done to verify the prediction of the modulation sidebands. The parameters of the spur gear pair in the experiment are shown in Table 1. Figure 8(a) shows the test gear box of a spur gear pair and Figure 8(b) shows the spur gear pair with the parameters given in Table 1. As shown in Figure 8(a), use a frequency converter to control the driving motor and a magnetic particle brake is used as the loader. The rated power of the drive motor is $0.55 \mathrm{~kW}$. The motor input current frequency ranges from 0 to $60 \mathrm{~Hz}$. Motor synchronous speed ranges from 0 to $1800 \mathrm{r} / \mathrm{min}$. The maximum braking current of the magnetic brake is $0.5 \mathrm{~A}$ and the maximum braking torque is $5 \mathrm{~N} \cdot \mathrm{m}$. A revolution speed transducer is used for measuring the revolution speed of driving gear and an acceleration sensor is mounted on the gear box of the input bearing.

Since the maximum synchronous speed of the motor is only $1800 \mathrm{r} / \mathrm{min}$, the experiment only verifies the system dynamics response at $1500 \mathrm{r} / \mathrm{min}$. The braking current is $0.4 \mathrm{~A}$. The sampling frequency of this experiment is $65536 \mathrm{~Hz}$ and the sampling time is $1 \mathrm{~s}$. The measured speed spectrum of input bearing at revolution speed of $1498 \mathrm{r} / \mathrm{min}$ is shown in Figure 9.

As shown in Figure 5(b), the sidebands at frequency of $f_{m}, 2 f_{m}, 3 f_{m}$, and $4 f_{m}$ can be resolved in the calculation results. However, as shown in Figure 9, the sidebands of the measured spectrum only appear at frequency of $f_{m}$ and $2 f_{m}$. There are two significant peaks at the meshing frequency and its $2 \mathrm{x}$ multiplier. The maximum peak appears at the meshing frequency of $1373 \mathrm{~Hz}$. There are eight significant peaks near the meshing frequency, at $1330 \mathrm{~Hz}, 1355 \mathrm{~Hz}, 1348 \mathrm{~Hz}, 1366 \mathrm{~Hz}$, $1380 \mathrm{~Hz}, 1391 \mathrm{~Hz}, 1398 \mathrm{~Hz}$, and $1416 \mathrm{~Hz}$, respectively.

As shown in Figure 5(b), there is a significant peak at the meshing frequency of $1375 \mathrm{~Hz}$ in the calculation result.

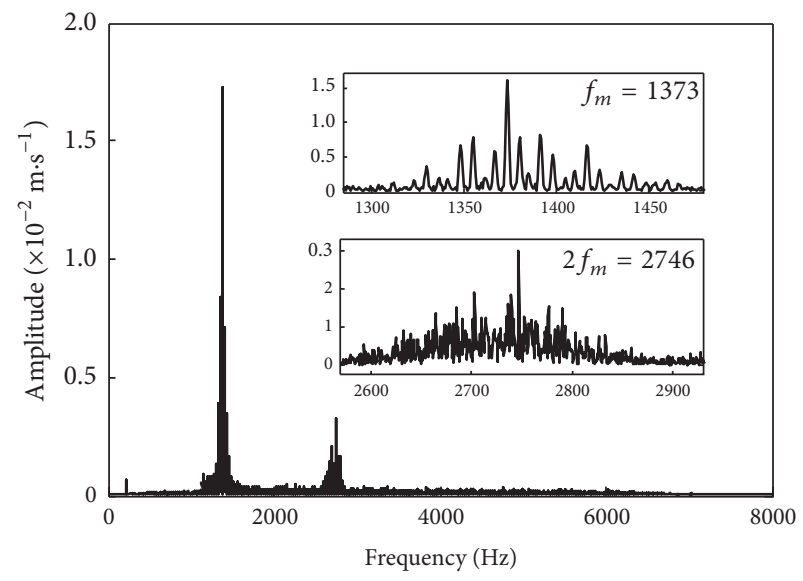

FIGURE 9: Speed spectrum of measured input bearing along $y$-axis.

There are also eight significant peaks near the meshing frequency, at $1332 \mathrm{~Hz}, 1350 \mathrm{~Hz}, 1357 \mathrm{~Hz}, 1368 \mathrm{~Hz}, 1382 \mathrm{~Hz}$, $1393 \mathrm{~Hz}, 1400 \mathrm{~Hz}$, and $1418 \mathrm{~Hz}$, respectively. At the frequency of $2 f_{m}$, both the calculated and the measured values show a significant peak. However, at the frequency of $2 f_{m}$, neither the calculated spectrum nor the measured spectrum shows significant symmetry. The measured peak value is slightly larger than the calculated one. The theoretical value and experimental values are basically consistent.

\section{Conclusion}

In this study, a 6 DOF dynamic model is established to predict modulation sidebands of a spur gear pair due to the modulation internal excitation. The spectrum of internal excitation is shown to contain sidebands because of the modulation timevarying mesh stiffness and modulation transmission errors caused by manufacturing errors and so forth. The sidebands of modulation internal excitation spectrum mainly appear around the mesh harmonic order at frequency of $f_{m}$ and 
$2 f_{m}$. Then the modulation internal excitation is applied to the spur gear pair and the dynamic equations are solved by Runge-Kutta method. As a result, the dynamic responses contain sidebands. At the end, the measured spectrums of spur gear pair acceleration are provided for comparisons to verify the dynamic responses predicted by the $6 \mathrm{DOF}$ model proposed in this paper. The calculated results are basically in conformity with the measured results.

\section{Conflicts of Interest}

The authors declare that there are no conflicts of interest regarding the publication of this paper.

\section{Acknowledgments}

This project is supported by the National Natural Science Foundation of China (no. 51675350), the PhD Startup Foundation of Liaoning Institute of Science and Technology (no. 1604B03), and the University Science Research Project of Liaoning Education Department (no. L2016lky02).

\section{References}

[1] H. N. Özgüven and D. R. Houser, "Mathematical models used in gear dynamics-a review," Journal of Sound and Vibration, vol. 121, no. 3, pp. 383-411, 1988.

[2] A. Kahraman and R. Singh, "Non-linear dynamics of a spur gear pair," Journal of Sound and Vibration, vol. 142, no. 1, pp. 49-75, 1990.

[3] A. Kahraman and R. Singh, "Non-linear dynamics of a geared rotor-bearing system with multiple clearances," Journal of Sound and Vibration, vol. 144, no. 3, pp. 469-506, 1991.

[4] A. Kahraman and R. Singh, "Interactions between time-varying mesh stiffness and clearance non-linearities in a geared system," Journal of Sound and Vibration, vol. 146, no. 1, pp. 135-156, 1991.

[5] G. W. Blankenship and A. Kahraman, "Steady state forced response of a mechanical oscillator with combined parametric excitation and clearance type non-linearity," Journal of Sound and Vibration, vol. 185, no. 5, pp. 743-765, 1995.

[6] Y. Cai and T. Hayashi, "Linear approximated equation of vibration of a pair of spur gears (theory and experiment)," Journal of Mechanical Design, Transactions Of the ASME, vol. 116, no. 2, pp. 558-564, 1994.

[7] Y. Cai, "Simulation on the rotational vibration of helical gears in consideration of the tooth separation phenomenon (a new stiffness function of helical involute tooth pair)," Journal of Mechanical Design, vol. 117, no. 3, pp. 460-469, 1995.

[8] Y. Shen, S. Yang, and X. Liu, "Nonlinear dynamics of a spur gear pair with time-varying stiffness and backlash based on incremental harmonic balance method," International Journal of Mechanical Sciences, vol. 48, no. 11, pp. 1256-1263, 2006.

[9] Y. Zhang, Q. Wang, H. Ma, J. Huang, and C. Zhao, "Dynamic analysis of three-dimensional helical geared rotor system with geometric eccentricity," Journal of Mechanical Science and Technology, vol. 27, no. 11, pp. 3231-3242, 2013.

[10] Y.-M. Zhang, J. Yang, P. Hu, and Q.-B. Wang, "Meshing characteristics analysis of spur gear pair considering modification coefficient," Journal of Northeastern University (Natural Science), vol. 34, no. 9, pp. 1287-1291, 2013.
[11] H. Ma, L. Zhu, Q. Wang, and Y. Zhang, "Modal coupling characteristic analysis of a helical gear rotor system with parallel shafts," Proceedings of the Chinese Society of Electrical Engineering, vol. 32, no. 29, pp. 131-136, 2012.

[12] L. Cui, X.-G. Song, and J.-R. Zheng, "Nonlinear dynamic analysis for a geared flexible rotor system considering multiclearance," Journal of Vibration and Shock, vol. 32, no. 8, pp. 171198, 2013 (Chinese).

[13] S. Li and A. Kahraman, "A tribo-dynamic model of a spur gear pair," Journal of Sound and Vibration, vol. 332, no. 20, pp. 49634978, 2013.

[14] J. Liu, S. Wang, S. Zhou et al., "Nonlinear behavior of a spur gear pair transmission system with backlash," Journal of Vibroengineering, vol. 16, no. 8, pp. 3850-3861, 2014.

[15] M. Inalpolat, M. Handschuh, and A. Kahraman, "Influence of indexing errors on dynamic response of spur gear pairs," Mechanical Systems and Signal Processing, vol. 60-61, pp. 391405, 2015.

[16] I. Atanasovska, “The mathematical phenomenological mapping in non-linear dynamics of spur gear pair and radial ball bearing due to the variable stiffness," International Journal of Non-Linear Mechanics, vol. 73, pp. 114-120, 2015.

[17] A. Fernández-del-Rincón, M. Iglesias, A. de-Juan, A. DiezIbarbia, P. García, and F. Viadero, "Gear transmission dynamics: effects of index and run out errors," Applied Acoustics, vol. 108, pp. 63-83, 2016.

[18] Z. Liu, Z. Liu, J. Zhao, and G. Zhang, "Study on interactions between tooth backlash and journal bearing clearance nonlinearity in spur gear pair system," Mechanism and Machine Theory, vol. 107, pp. 229-245, 2017.

[19] K. Huang, Y. Xiong, T. Wang, and Q. Chen, "Research on the dynamic response of high-contact-ratio spur gears influenced by surface roughness under EHL condition," Applied Surface Science, vol. 392, pp. 8-18, 2017.

[20] G. W. Blankenship and R. Singh, "Analytical solution for modulation sidebands associated with a class of mechanical oscillators," Journal of Sound and Vibration, vol. 179, no. 1, pp. 13-36, 1995.

[21] F. Chaari, W. Bartelmus, R. Zimroz, T. Fakhfakh, and M. Haddar, "Gearbox vibration signal amplitude and frequency modulation," Shock and Vibration, vol. 19, no. 4, pp. 635-652, 2012. 


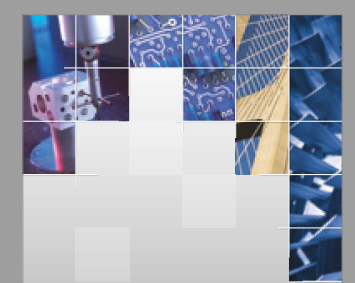

\section{Enfincering}
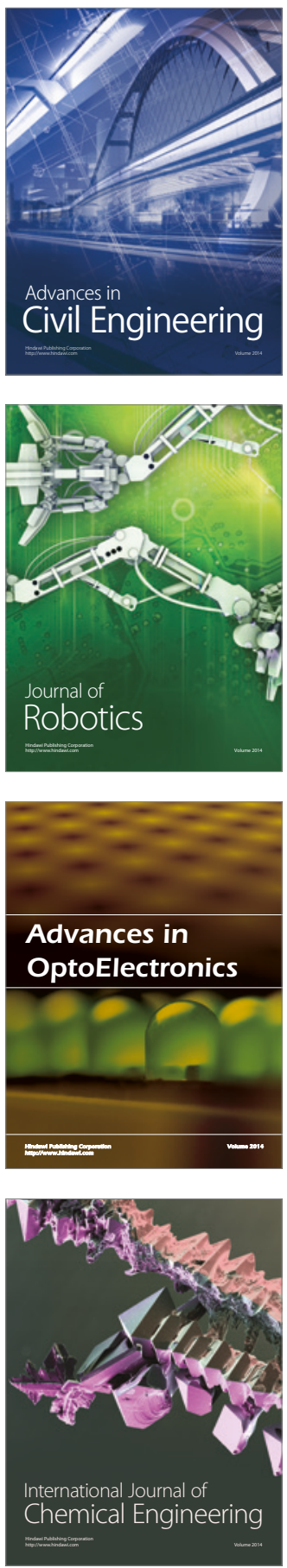

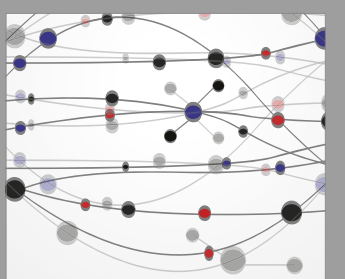

The Scientific World Journal

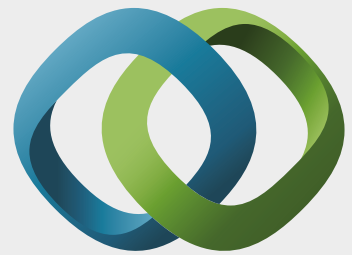

\section{Hindawi}

Submit your manuscripts at

https://www.hindawi.com
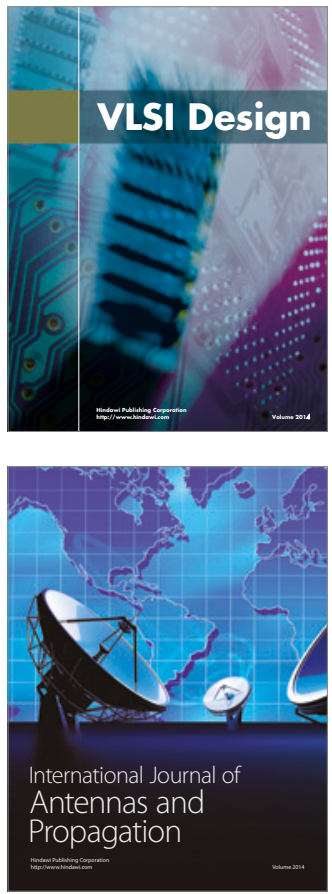

\section{Rotating}

Machinery
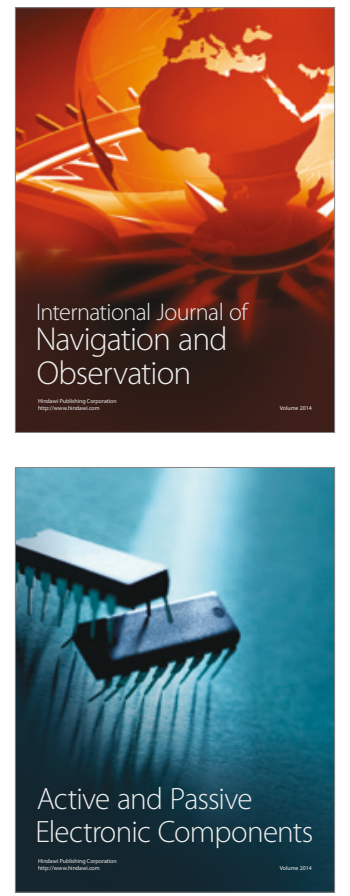
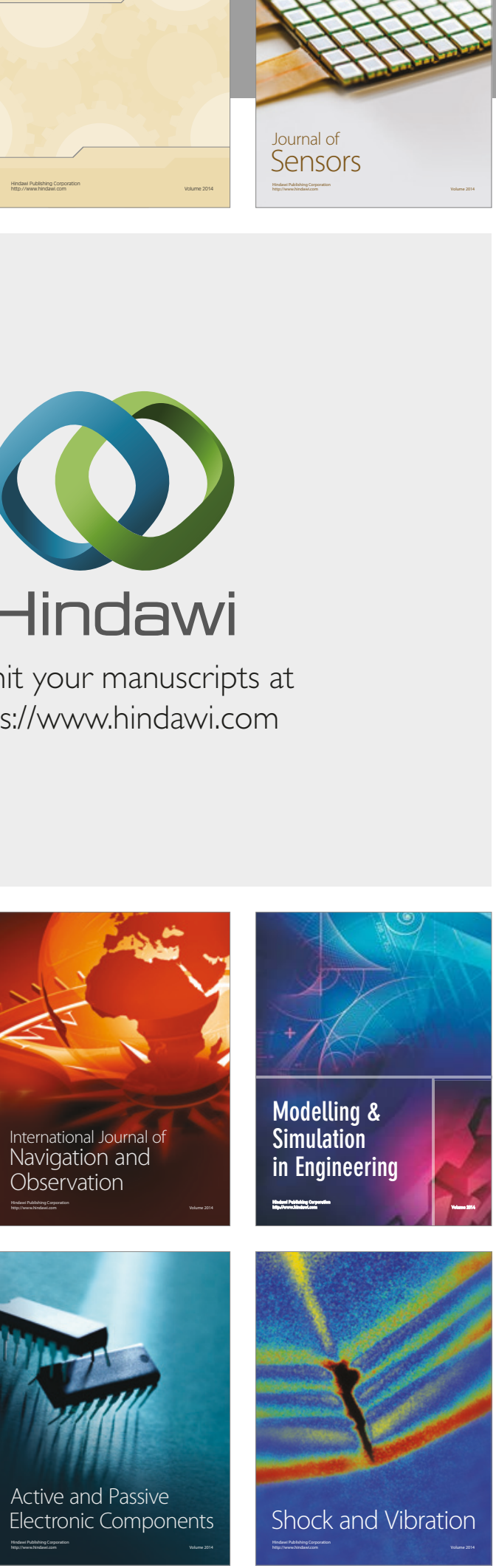
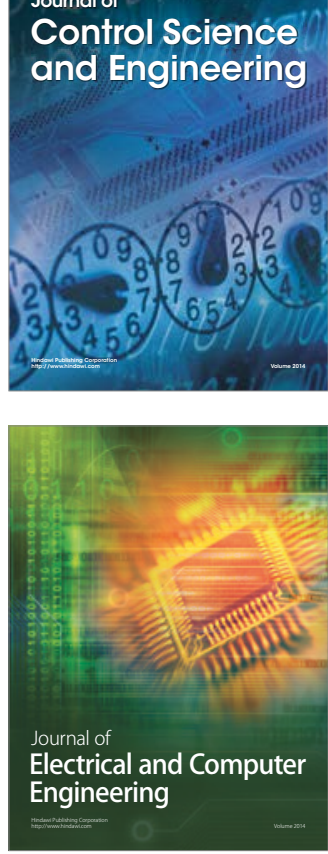

Distributed

Journal of

Control Science

and Engineering
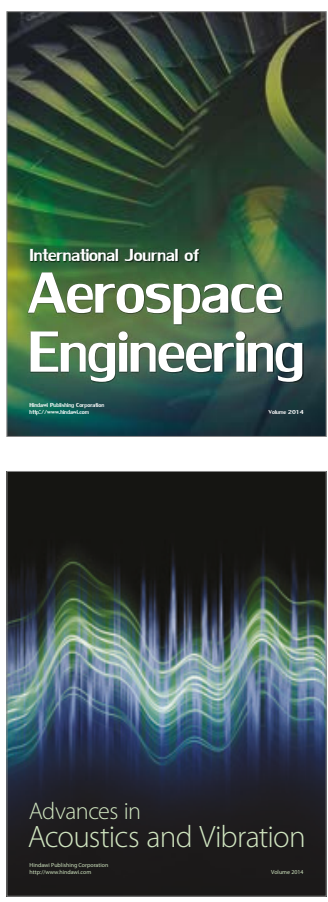

Sensor Networks 